\title{
Japanese Society of Clinical Oncology clinical practice guidelines 2010 for antiemesis in oncology: executive summary
}

\author{
Hideki Takeuchi ${ }^{1,2} \cdot$ Toshiaki Saeki $^{2} \cdot$ Keisuke Aiba $^{3} \cdot$ Kazuo Tamura $^{4}$. \\ Kenjiro Aogi ${ }^{5} \cdot$ Kenji Eguchi $^{6} \cdot \mathrm{Kenji}$ Okita $^{7} \cdot$ Yoshikazu Kagami $^{8} \cdot$ Ryuhei Tanaka9 $^{9}$ \\ Kazuhiko Nakagawa ${ }^{10} \cdot$ Hirofumi Fujii $^{11} \cdot$ Narikazu Boku $^{12} \cdot$ Makoto Wada $^{13}$. \\ Tatsuo Akechi $^{14}$. Yasuhiro Udagawa ${ }^{15}$. Yutaka Okawa ${ }^{3}$. Yusuke Onozawa ${ }^{16}$. \\ Hidenori Sasaki $^{17}$ - Yasuo Shima ${ }^{18} \cdot$ Naohito Shimoyama $^{19} \cdot$ Masayuki Takeda $^{10}$. \\ Toshihiko Nishidate $^{7} \cdot$ Akifumi Yamamoto $^{20}$ - Tadashi Ikeda ${ }^{21} \cdot$ Koichi Hirata $^{7}$
}

Received: 7 May 2015 / Accepted: 20 May 2015 / Published online: 17 June 2015

(C) Japan Society of Clinical Oncology 2015

\begin{abstract}
The purpose of this article is to disseminate the standard of antiemetic therapy for Japanese clinical oncologists. On the basis of the Appraisal of Guidelines for Research and Evaluation II instrument, which reflects evidence-based clinical practice guidelines, a working group of the Japanese Society of Clinical Oncology (JSCO) reviewed clinical practice guidelines for antiemesis and performed a systematic review of evidence-based domestic practice guidelines for antiemetic therapy in Japan. In addition, because
\end{abstract}

Toshiaki Saeki

tsaeki@saitama-med.ac.jp

1 Department of Breast Oncology, Saitama Medical University, Saitama, Japan

2 Department of Breast Oncology, Saitama Medical University International Medical Center, Saitama, Japan

3 Division of Clinical Oncology/Hematology, Department of Internal Medicine, Jikei University School of Medicine, Tokyo, Japan

4 Division of Medical Oncology, Hematology and Infectious Disease, Department of Medicine, Fukuoka University Hospital, Fukuoka, Japan

5 Department of Breast Oncology, National Hospital Organization Shikoku Cancer Center, Matsuyama, Ehime, Japan

6 Department of Internal Medicine and Medical Oncology, Teikyo University School of Medicine, Tokyo, Japan

7 Department of Surgery, Surgical Oncology and Science, Sapporo Medical University Postgraduate School of Medicine, Sapporo, Hokkaido, Japan

8 Division of Radiation Oncology, Department of Radiology, Showa University School of Medicine, Tokyo, Japan

9 Department of Pediatric Hematology and Oncology, Saitama Medical University International Medical Center, Saitama, Japan health-insurance systems in Japan are different from those in other countries, a consensus was reached regarding standard treatments for chemotherapy that induce nausea and vomiting. Current evidence was collected by use of MEDLINE, from materials from meetings of the American Society of Clinical Oncology National Comprehensive Cancer Network, and from European Society of Medical Oncology/ Multinational Association of Supportive Care in Cancer guidelines for antiemesis. Initially, 21 clinical questions (CQ)

10 Department of Medical Oncology, Faculty of Medicine, Kinki University, Osaka, Japan

11 Department of Clinical Oncology, Jichi Medical University, Tochigi, Japan

12 Gastrointestinal Medical Oncology Division, National Cancer Center Hospital, Tokyo, Japan

13 Department of Psycho-Oncology and Palliative Medicine, Osaka Medical Center for Cancer and Cardiovascular Diseases, Osaka, Japan

14 Department of Psychiatry and Cognitive-Behavioral Medicine, Nagoya City University Graduate School of Medical Sciences, Nagoya, Aichi, Japan

15 Department of Obstetrics and Gynecology, Fujita Health University School of Medicine, Toyoake, Aichi, Japan

16 Division of Clinical Oncology, Shizuoka Cancer Center, Shizuoka, Japan

17 Department of Medical Oncology, National Hospital Organization Kanmon Medical Center, Yamaguchi, Japan

18 Department of Palliative Medicine, Tsukuba Medical Center Hospital, Tsukuba, Ibaraki, Japan

19 Department of Anesthesiology, Jikei University School of Medicine, Tokyo, Japan 
were selected on the basis of CQs from other guidelines. Patients treated with highly emetic agents should receive a serotonin (5-hydroxytryptamine; $5 \mathrm{HT}_{3}$ ) receptor antagonist, dexamethasone, and a neurokinin 1 receptor antagonist. For patients with moderate emetic risk, $5 \mathrm{HT}_{3}$ receptor antagonists and dexamethasone were recommended, whereas for those receiving chemotherapy with low emetic risk dexamethasone only is recommended. Patients receiving high-emetic-risk radiation therapy should also receive a $5 \mathrm{HT}_{3}$ receptor antagonist. In this paper the 2010 JSCO clinical practice guidelines for antiemesis are presented in English; they reveal high concordance of Japanese medical circumstances with other antiemetic guidelines that are similarly based on evidence.

Keywords Antiemetic treatment - Cancer chemotherapy · Clinical practice guideline

\section{Introduction}

Recent developments in cancer chemotherapy have improved the survival of patients with a variety of malignancies. However, antiemetic treatments for chemotherapy which induce nausea and vomiting (CINV) are critical for successful chemotherapy. Consensus and/or evidencebased guidelines for antiemetic treatment in oncology have been issued by the National Comprehensive Cancer Network (NCCN) [1], the Multinational Association of Supportive Care in Cancer (MASCC)/European Society of Medical Oncology (ESMO) [2], and the American Society of Clinical Oncology (ASCO) [3]. However, application of these guidelines in Japan is limited because of different clinical circumstances and different domestic insurance coverage. Hence the Japanese clinical practice guideline for antiemetics was established and published on May 1st, 2010 as the first publication of the Japanese Society of Clinical Oncology (JSCO).

\section{Methods}

Initially, JSCO selected members of a working group for these guidelines on the basis of the Appraisal of Guidelines for Research and Evaluation (AGREE) II instrument [4], which assesses the methods used to generate evidence-based clinical practice guidelines.

\footnotetext{
20 Department of Skin Oncology/Dermatology, Saitama Medical University International Medical Center, Saitama, Japan

21 Department of Surgery, Teikyo University School of Medicine, Tokyo, Japan
}

The members of a working group were included medical oncologists, oncological surgeons, palliative care physicians, and psycho-oncologists. The AGREE II Instrument is available as a PDF or in electronic form from http://www.agreetrust.org/resource-centre/agreeii/. A draft of the guidelines was developed systematically, and members of the medical staff were in unanimous agreement with regard to all recommendations for treatment and clinical questions (CQ). However, domestic factors including ethnicity and health policy formation at the system level required further consideration. Hence, a consensus of all medical practitioners was held at a consensus meeting, and recommendations for antiemetic treatments were discussed in the context of Japanese medical circumstances.

\section{Literature search strategy}

A systematic review and meta-analysis of the effectiveness of antiemetic therapy was performed by use of the major international guidelines NCCN, MASSC/ESMO, and ASCO as sources of information [1-3]. Subsequently, high-level evidence was selected from the literature, and structured abstracts were generated for each of the manuscripts included. MEDLINE searches were also performed to identify other randomized controlled trials, and the Cochrane library was reviewed during 20082010 [5]. Materials from ASCO and MASSC annual meetings were reviewed and some Japanese manuscripts containing sufficiently strong evidence were included. Materials that were available in abstract form only were not considered.

\section{Inclusion criteria for published studies}

Systematic reviews and reports of randomized controlled trials were included if the intervention was for treatment of nausea or vomiting after cancer therapy, and nausea and/or vomiting outcomes were reported. This guideline was reviewed and approved by the JSCO Clinical Practice Guidelines Committee and the Board of Directors, and was reviewed and approved for publication in the International Journal of Clinical Oncology.

\section{Guidelines and conflicts of interest}

The Update Committee was assembled in accordance with ASCO's Conflict of Interest (COI) Management Procedures for Clinical Practice Guidelines ("Procedures", summarized at http://www.asco.org/guidelinescoi). The members of the working group provided disclosure forms that required disclosure of financial and other interests to the board of directors of JSCO. Subsequently, the COI 
committee reviewed the COI of each member and allowed all members without COIs to contribute to the guideline.

\section{Recommendation grade}

Recommendation grades were stated as follows:
A Strongly recommended clinical action
B Recommended clinical action
C1 Clinical action may be useful although there is a lack of high-level scientific evidence
C2 Not recommended because of insufficient scien- tific evidence
D Clinical action not recommended

\section{Results}

The working group of JSCO clinical practice guidelines for antiemesis adopted a clinical question (CQ) form as the main guideline format and selected the following $21 \mathrm{CQs}$ :

CQ1. How is the emetic risk induced by cancer chemotherapy categorized?

Recommendation (Grade A): the emetic risk induced by cancer chemotherapy is classified as high, moderate, low, and minimum according to the frequency of patient nausea and vomiting experiences, and antiemetic prophylactic treatments are prescribed in accordance with these categories.

The emetic risks of cancer chemotherapy depend on the potential emetogenicity of combined chemotherapeutic regimens. The emetic risk is evaluated on the basis of the percentage of untreated patients who experience acute emesis within $24 \mathrm{~h}$ of initiation and/or administration of cancer chemotherapy and is categorized as follows:

High emetic risk: $90 \%$ or more patients experience acute emesis

Moderate emetic risk: $30-90 \%$ of patients experience acute emesis

Low emetic risk: $10-30 \%$ of patients experience acute emesis

Minimum emetic risk: fewer than $10 \%$ of patients experience acute emesis

CQ2. How are intravenous chemotherapeutic agents categorized for the emetic risk?

Recommendation (Grade A): proper and sufficient antiemetic prophylaxis should be recommended in accordance with the four risk categories (Table 1).

Recommendation (Grade $\mathrm{C} 1$ ): antiemetic treatments for domestic chemotherapeutic agents developed in Japan are uncertain because of limited evidence of drug efficacy and low frequency of usage.
Emetic risks of chemotherapeutic agents are classified in Table 1 on the basis of the recommendations of existing guidelines produced with a high level of consensus, for example NCCN, MASSC, and ASCO; they were modified in consideration of particular clinical circumstances in Japan $[6,7]$. Most chemotherapeutic regimens with high or moderate emetic risk include intravenous chemotherapeutic agents, and proper and flexible management of their emetic risks is essential because they are usually administered over several days and include several drugs. Although the 2009 NCCN guidelines indicate that high and low-dose cisplatin regimens have high and moderate emetic risk, respectively, the 2008 MASCC and 2006 ASCO guidelines categorized cisplatin as a drug of high emetic risk irrespective of dosage $[8,9]$. Accordingly, all cisplatin regimens, including those administered over several days were regarded as regimens of high emetic risk (CQ10). However, combined regimens that include anthracycline and cyclophosphamide, for example AC, CAF, EC, and FEC, are usually regarded as having high emetogenicity. The $2009 \mathrm{NCCN}$ guidelines categorized these anthracycline-containing regimens as high emetic risk similar to other monotherapeutic agents with high emetogenicity. Hence, this categorization was used for all anthracycline-containing regimens.

CQ3. How are the emetic risk categories for oral chemotherapeutic agents defined and managed?

Recommendation (Grade C1): according to clinical study protocols designed to assess efficacy as supportive co-treatments, suspension and/or dose reduction of chemotherapeutic agents should be considered to limit nausea and vomiting to grade 3 or less.

The emetic risk of oral chemotherapeutic agents is listed in Table 2. In Japan, oral fluoropyrimidine-based regimens are frequently used as adjuvant treatments with tegafur-uracil and/or leucovorin and capecitabine for colorectal cancer, S-1 for gastric cancer, and tegafur-uracil for breast and lung cancers, and several clinical trials have demonstrated efficacy is reasonable. Moreover, the Japanese clinical practice guidelines have indicated that S-1 and tegafur-uracil and/or leucovorin are efficacious treatment strategies for advanced gastric and colorectal cancers. Although these oral chemotherapeutic agents have lower emetogenicity when administered alone, adverse digestive events occur after repeated daily administration. Hence, antiemetic treatments are important to achieving higher drug adherence and to optimizing treatment.

CQ4. How should acute nausea and vomiting induced by cancer chemotherapy be prevented?

Recommendation (Grade A): a triple regimen of neurokinin 1 (NK1) receptor antagonist (aprepitant), serotonin (5-hydroxytryptamine: $5 \mathrm{HT}_{3}$ ) receptor antagonist, and dexamethasone is recommended for acute emesis during highly emetic cancer chemotherapy. 
Table 1 Emetic risk category for intravenous chemotherapeutic agents

\begin{tabular}{|c|c|c|}
\hline JSCO emetic risk category & Agent (regimen) & \\
\hline High emetic risk (emetic frequency $>90 \%$ ) & $\begin{array}{l}\text { Cisplatin } \\
\text { Cyclophosphamide }\left(>1500 \mathrm{mg} / \mathrm{m}^{2}\right) \\
\text { Dacarbazine } \\
\text { Doxorubicin + cyclophosphamide } \\
\text { Epirubicin + cyclophosphamide }\end{array}$ & $\begin{array}{l}\text { Altretaine } \\
\text { Carmustine }\left(>250 \mathrm{mg} / \mathrm{m}^{2}\right) \\
\text { Mechlorethamine } \\
\text { Streptozocin }\end{array}$ \\
\hline Moderate emetic risk (emetic frequency $30-90 \%$ ) & $\begin{array}{l}\text { Actinomycin D } \\
\text { Amrubicin } \\
\text { Arsenic trioxide } \\
\text { Busulfan ( }>4 \mathrm{mg} / \text { day }) \\
\text { Carboplatin } \\
\text { Cyclophosphamide }\left(\leq 1500 \mathrm{mg} / \mathrm{m}^{2}\right) \\
\text { Cytarabine }\left(>200 \mathrm{mg} / \mathrm{m}^{2}\right) \\
\text { Daunorubicin } \\
\text { Doxorubicin } \\
\text { Enocitabine } \\
\text { Epirubicin } \\
\text { Idarubicin } \\
\text { Ifosphamide } \\
\text { Interferon } \alpha\left(\geq 10 \text { million } \mathrm{IU} / \mathrm{m}^{2}\right) \\
\text { Interleukin-2 }\left(>12-15 \text { million } \mathrm{IU} / \mathrm{m}^{2}\right)\end{array}$ & $\begin{array}{l}\text { Irinotecan } \\
\text { Melphalan }\left(\geq 50 \mathrm{mg} / \mathrm{m}^{2}\right) \\
\text { Methotrexate }\left(\geq 250 \mathrm{mg} / \mathrm{m}^{2}\right) \\
\text { Nedaplatin } \\
\text { Oxaliplatin }\left(\geq 75 \mathrm{mg} / \mathrm{m}^{2}\right) \\
\text { Temozolomide } \\
\text { Therarubicin } \\
\left.\text { Amifostine ( } \geq 300 \mathrm{mg} / \mathrm{m}^{2}\right) \\
\text { Azacitidine } \\
\text { Bendamustine } \\
\text { Carmustine }\left(\leq 250 \mathrm{mg} / \mathrm{m}^{2}\right) \\
\text { Clofarabine }\end{array}$ \\
\hline Low emetic risk (emetic frequency $10-30 \%$ ) & $\begin{array}{l}\text { Interleukin-2 }\left(\leq 12 \mathrm{million} \mathrm{IU} / \mathrm{m}^{2}\right) \\
\text { Cytarabine }\left(100-200 \mathrm{mg} / \mathrm{m}^{2}\right) \\
\text { Docetaxel } \\
\text { Etoposide } \\
5 \text {-Fluorouracil } \\
\text { Gemcitabine } \\
\text { Interferon } \alpha\left(5-10 \text { million } \mathrm{IU} / \mathrm{m}^{2}\right) \\
\text { Liposomal doxorubicin } \\
\text { Methotrexate }\left(50-250 \mathrm{mg} / \mathrm{m}^{2}\right) \\
\text { Mitomycin C }\end{array}$ & $\begin{array}{l}\text { Mitoxantrone } \\
\text { Nab-paclitaxel } \\
\text { Nimustine } \\
\text { Paclitaxel } \\
\text { Pemetrexed } \\
\text { Pentostatin } \\
\text { Ranimusutine } \\
\text { Topotecan } \\
\text { Amifostine }(<300 \mathrm{mg}) \\
\text { Ixabepilone }\end{array}$ \\
\hline Minimum emetic risk (emetic frequency: $<10 \%$ ) & $\begin{array}{l}\text { L-Asparaginase } \\
\text { Bevacizumab } \\
\text { Bleomycin } \\
\text { Bortezomib } \\
\text { Cetuximab } \\
\text { Cladribine } \\
\text { Cytarabine }\left(<100 \mathrm{mg} / \mathrm{m}^{2}\right) \\
\text { Fludarabine } \\
\text { Gemtuzumab ozogamicin } \\
\text { Methotrexate }\left(\leq 50 \mathrm{mg} / \mathrm{m}^{2}\right) \\
\text { Nelarabine } \\
\text { Peplomycin } \\
\text { Rituximab }\end{array}$ & $\begin{array}{l}\text { Vinblastine } \\
\text { Vincristine } \\
\text { Vinorelbine } \\
\text { Trastuzumab } \\
\text { Vindesine } \\
\text { Alemtuzumab } \\
\text { Decitabine } \\
\text { Denileukin diftitox } \\
\text { Dexrazoxane } \\
\text { Panitumumab } \\
\text { Pegaspargase } \\
\text { Temsirolimus } \\
\text { Valrubicin }\end{array}$ \\
\hline
\end{tabular}

Agents in italics are not approved for clinical use in Japan

Recommendation (Grade A): regimens containing $5 \mathrm{HT}_{3}$ receptor antagonists and dexamethasone are basically recommended for acute emesis during moderately emetic cancer chemotherapy. For particular chemotherapeutic regimens, addition of an NK1 receptor antagonist to regimens of $5 \mathrm{HT}_{3}$ receptor antagonist and dexamethasone are considered. 
Table 2 Emetic risk category for oral chemotherapeutic agents

\begin{tabular}{|c|c|c|}
\hline JSCO emetic risk category & Agent (regimen) & \\
\hline High emetic risk (emetic frequency $>90 \%$ ) & Procarbazine & \\
\hline Moderate emetic risk (emetic frequency $30-90 \%$ ) & $\begin{array}{l}\text { Cyclophosphamide } \\
\text { Etoposide } \\
\text { Imatinib }\end{array}$ & $\begin{array}{l}\text { Temozolomide } \\
\text { Vinorelbine }\end{array}$ \\
\hline Low emetic risk (emetic frequency $10-30 \%$ ) & $\begin{array}{l}\text { Capecitabine } \\
\text { Doxifluridine } \\
\text { Mercaptopurine } \\
\text { Nilotinib }\end{array}$ & $\begin{array}{l}\text { S-1 } \\
\text { Sobuzoxane Tegafur-Uracil (UFT) }\end{array}$ \\
\hline Minimum emetic risk (emetic frequency $<10 \%$ ) & $\begin{array}{l}\text { Dasatinib } \\
\text { Erlotinib } \\
\text { Fludarabine } \\
\text { Gefitinib } \\
\text { Hydroxyurea } \\
\text { Lapatinib } \\
\text { Melphalan } \\
\text { Methotrexate }\end{array}$ & $\begin{array}{l}\text { Sorafenib } \\
\text { Sunitinib } \\
\text { Thalidomide } \\
\text { Tretinoin } \\
\text { Tamibarotene } \\
\text { Chlorambucil } \\
\text { 6-Thioguanine }\end{array}$ \\
\hline
\end{tabular}

Agents in italics are not approved for clinical use in Japan

Acute onset of nausea and vomiting occurs within a few minutes to several hours, and intensity generally peaks from 5 to $6 \mathrm{~h}$ after administration of chemotherapy and usually recovers within $24 \mathrm{~h}$. Management and control of CINV are essential for successful cancer chemotherapy, because unfavorable side effects of nausea and vomiting are associated with poor treatment adherence and effects. In addition, incomplete prevention of acute emesis may lead to uncontrollable delayed emesis [10]. Hence, according to the four emetic risk categories indicated in CQ2 and 3, appropriate and sufficient antiemetic treatments are needed from the start of chemotherapy. The standard model of antiemetic treatment regimens is detailed in the four diagrams in Fig. 1. In the high emetic risk diagram, evidence of antiemetic actions of $\mathrm{AC}$ regimens was taken from clinical trials of other highly emetic cancer agents, and suggests no additional effects of dexamethasone after day 2. Upon issue of the 1st guideline, oral aprepitant was the only NK1 receptor antagonist available for clinical use in Japan. Subsequently, in November 2011, the Japanese Ministry of Health, Labour, and Welfare approved the intravenous NK1 receptor antagonist, fosaprepitant. Accordingly, we immediately modified the diagram and included additional information about fosaprepitant as a minor revision of the guideline, with careful consideration of the limited evidence of its efficacy and safety.

CQ5. How should delayed nausea and vomiting after cancer chemotherapy be prevented?

Recommendation (Grade A): a combined regimen of NK1 receptor antagonist (aprepitant) and dexamethasone is recommended for treatment of delayed emesis during highly emetic cancer chemotherapy.

Recommendation (Grade A): single administration of dexamethasone is basically recommended for delayed emesis during moderately emetic cancer chemotherapy. However, regimens of NK1 antagonist and/or dexamethasone are considered.

Delayed onset of nausea and vomiting occurs later than $24 \mathrm{~h}$ after administration of chemotherapy. In these circumstances, control of delayed emesis is essential to maintaining patients' quality of life and for motivating further treatment with a healthy mentality. As described in CQ4, complete prevention of acute emesis is the most important and fundamental strategy for preventing delayed emesis (Fig. 1). In specific cases in which dexamethasone should be restricted, 2-4 days of 5HT3 antagonist is recommended instead of dexamethasone.

CQ6. What kinds of serotonin $\left(5 \mathrm{HT}_{3}\right)$ receptor antagonist are available in Japan?

Recommendation (Grade A): $5 \mathrm{HT}_{3}$ receptor antagonists are effective treatments for prevention of nausea and vomiting during cancer chemotherapy; seven drugs are approved in Japan: granisetron, palonosetron, ramosetron, ondansetron, tropisetron, azasetron, and indisetron.

Several $5 \mathrm{HT}_{3}$ receptor antagonists are currently available in Japan, and efficacy for management of CINV has been demonstrated for all these agents, particularly under conditions of acute phase emesis. However, the efficacy of these agents for treatment of delayed emesis remains controversial because no further antiemetic effects of additional treatments have been observed after initial use 
Fig. 1 Antiemetic treatments for intravenous cancer chemotherapy. a High emetic risk: in the absence of aprepitant, 13.2-16.4 mg dexamethasone should be given on day 1; b moderate emetic risk; c low emetic risk; d minimum emetic risk. Asterisk, optional fosaprepitant was added to the diagrams in a revised edition (version 1.2). Double asterisk, optional dose of dexamethasone. The diagrams indicate standard examples of antiemetic treatment regimens. Flexible modifications are necessary according to specific conditions of each patient. Intravenous dexamethasone contains $3.3 \mathrm{mg} / \mathrm{mL}$ dexamethasone out of a total $4 \mathrm{mg} / \mathrm{mL}$ dexamethasone sodium phosphate a

\begin{tabular}{|c|c|c|c|c|c|c|}
\hline \multirow{2}{*}{$\begin{array}{c}\text { High } \\
\text { emetic risk }\end{array}$} & 1 & 2 & 3 & 4 & 5 & day \\
\hline & (Pre-me & & & & & \\
\hline
\end{tabular}

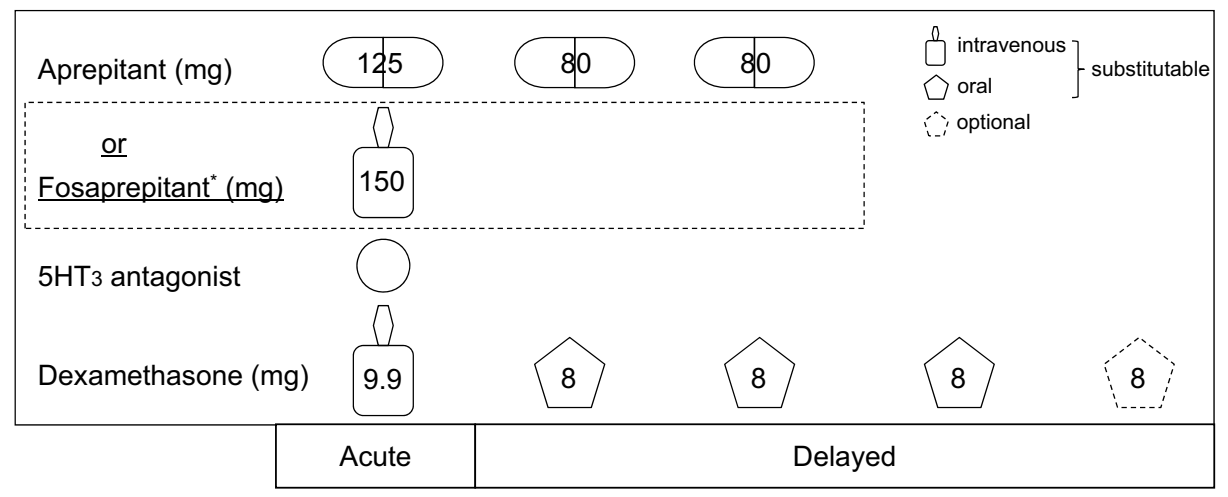

\section{b}

\begin{tabular}{l|cccccc}
\hline $\begin{array}{l}\text { Moderate } \\
\text { emetic risk }\end{array}$ & 1 & 2 & 3 & 4 & 5 & day \\
\cline { 3 - 6 } & (Pre-medication) & & & &
\end{tabular}

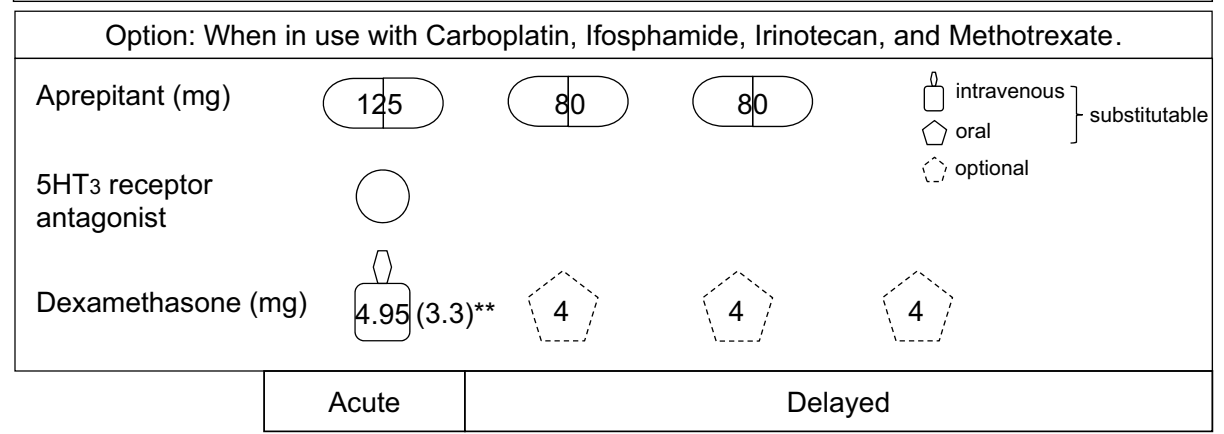

C

\begin{tabular}{|c|ccccc}
\hline $\begin{array}{c}\text { Low } \\
\text { emetic risk }\end{array}$ & 1 & 2 & 3 & 4 & 5 day \\
\cline { 4 - 5 } & (Pre-medication) & & & & \\
\hline
\end{tabular}

\begin{tabular}{|l|l|l|}
\hline \multicolumn{2}{|l|}{ Dexamethasone $(\mathrm{mg})$} & \\
\hline & Acute & \\
\hline
\end{tabular}

\section{d}

\begin{tabular}{|c|ccccc|}
\hline $\begin{array}{c}\text { Minimal } \\
\text { emetic risk }\end{array}$ & 1 & 2 & 3 & 4 & 5 \\
\hline \\
Antiemetic treatment is NOT recommended.
\end{tabular}

of $5 \mathrm{HT}_{3}$ receptors with antagonistic agents. It has been proved that palonosetron is not inferior to granisetron in the acute phase and is superior to granisetron in the delayed phase [11].
CQ7. What is the recommended dose of corticosteroid for antiemetic treatment?

Recommendation (Grade A): corticosteroid is an effective antiemetic at recommended doses determined 
according to the emetic risk categories of chemotherapeutic regimens.

Corticosteroid has been used as an antiemetic prophylactic during cancer chemotherapy for 25 years [12], although its mechanism of action remains unclear compared with those of $5 \mathrm{HT}_{3}$ and NK1 antagonists, which have recently been approved with clear evidence of mechanisms. Although several classes of corticosteroid are available, dexamethasone and methylprednisolone are most frequently used as antiemetics, with strong evidence of their effects $[13,14]$. In particular, oral and intravenous dexamethasone (4-20 mg/day) has been approved as antiemetic treatment during cancer chemotherapy in Japan. However, the efficacy of high-dose dexamethasone has not been compared with that of 20-mg treatments among either Western [13, 14] or Japanese populations [15].

CQ8. How should breakthrough nausea and vomiting be managed?

Recommendation (Grade B): fixed around-the-clock administration of a variety of drugs should be considered according to patient symptoms. In addition, antiemetic $5 \mathrm{HT}_{3}$ receptor antagonists should be replaced with another type of $5 \mathrm{HT}_{3}$ receptor antagonist.

Breakthrough emesis refers to nausea and vomiting despite prophylactic antiemetic treatment, and requires additional treatment with antiemetic agents with mechanisms of action that differ from that of the primary antiemetic agent. Among these, the dopamine antagonists metoclopramide, butyrophenone, corticosteroid, and lorazepam may be considered for breakthrough emesis, despite poor evidence of their efficacy. A systematic review of antiemetic treatments for patients with advanced cancer showed that metoclopramide is superior to placebo and equivalent to ondansetron, although responses were only $23-36 \%$ and $18-52 \%$ for nausea and vomiting, respectively [16]. Moreover, a randomized clinical controlled study of 51 advanced cancer patients showed no significant effects of additional dexamethasone for nausea after failure of antiemetic response to metoclopramide [17].

Some reports recommend antiemetic prophylaxis using agents that are not $5 \mathrm{HT}_{3}$ receptor antagonists.

CQ9. How should acute nausea and vomiting induced by low and minimum emetic chemotherapy be managed?

Recommendation (Grade B): during low emetic chemotherapy, dexamethasone should be considered according to chemotherapeutic regimen and patient background.

Recommendation (Grade $\mathrm{C} 1$ ): routine usage of dexamethasone is not recommended for minimum emetic chemotherapy.

Prophylactic antiemetic treatment is not recommended for low or minimum emetic chemotherapy, because patients do not progress to definite nausea and vomiting. Nonetheless, some patients suffer from emesis during treatment with low or minimum emetic chemotherapy, necessitating flexible and appropriate treatment despite the absence of high-level evidence. The 2006 ASCO and 2008 MASCC guidelines recommended administration of 4-8 mg dexamethasone [13, 18], and include prochlorperazine [19] and metoclopramide as optional antiemetics.

CQ10. How is nausea and vomiting managed for such regimens as several cisplatin treatments daily?

Recommendation (Grade B): a triple antiemetic regimen of $5 \mathrm{HT}_{3}$ antagonist, dexamethasone, and aprepitant is recommended for acute nausea and vomiting during more typical chemotherapeutic regimens. A double regimen of dexamethasone and aprepitant is recommended for delayed nausea and vomiting, even during regimens of several cisplatin treatments daily.

It is widely accepted that cisplatin is a highly emetic chemotherapeutic agent, and it is commonly administered every 3 or 4 weeks at $\geq 50 \mathrm{mg} / \mathrm{m}^{2}$ for treatment of a variety of malignancies. However, different cisplatin regimens have been established with reasonable evidence, including several cisplatin treatments daily at $<50 \mathrm{mg} / \mathrm{m}^{2}$ for oncologic tumors such as cholangiocarcinomas, bladder cancers, and germinomas [20,21], and continuous cisplatin injections at $100 \mathrm{mg} / \mathrm{m}^{2}$ over 4 days for non-Hodgkin malignant lymphomas.

CQ11. How should anticipatory nausea and vomiting be managed?

Recommendation (Grade B): initially, complete prevention of emesis is essential during acute and delayed phases, so patients never experience nausea and vomiting.

Recommendation (Grade B): benzodiazepine is effective for anticipatory nausea and vomiting.

Recommendation (Grade B): such psychological therapy as systematic desensitization and/or behavioral treatment, relaxation therapy, and hypnotherapy for pediatric patients effectively ameliorate anticipatory nausea and vomiting.

Anticipatory nausea and vomiting occurs immediately before treatment, and reflects previous negative experiences of cancer chemotherapy [22-24], although nausea is more common than vomiting among such cases. The ideal prophylaxis for this symptom is complete prevention of emesis from the initial treatment [23-26]. Hence, appropriate antiemetic treatments are essential, and require accurate assessment of emetic risks for planned chemotherapeutic regimens. The 2009 NCCN and 2008 MASCC guidelines recommended treatments with lorazepam [27] for anticipatory nausea and vomiting, and alprazolam [28] for anticipatory nausea.

CQ12. How are emetic risks categorized for radiation therapy?

Recommendation (Grade A): emetic risks of radiation therapy are classified (Table 3) according to tissue targets and volumes for irradiation. 
Table 3 Emetic risk category for radiation therapy

\begin{tabular}{lll}
\hline JSCO emetic risk category & Treated area & \\
\hline High emetic risk (emetic frequency: $>90 \%$ ) & Total body & \\
Moderate emetic risk (emetic frequency: $30-90 \%)$ & Upper abdomen & \\
Low emetic risk (emetic frequency: $10-30 \%)$ & Lower thorax & Pelvis \\
& Cranium (radiosurgery) & Craniospinal \\
Minimum emetic risk (emetic frequency: $<10 \%)$ & Head and neck & Extremities \\
& Cranium & Breast \\
\hline
\end{tabular}

As for chemotherapy, antiemetic treatments for radiation therapy are critical for successful treatment. Accordingly, the 2004 MASCC and 2006 ASCO guidelines indicate the emetic risk categories for specific targeted tissues, and recommend prophylactic emetic regimens based on these risk classifications. The risk of radiation-induced nausea and vomiting is categorized according to the percentage of patients who experience emesis. Moreover, whole body and upper abdominal radiation therapy are likely to cause greater emesis, and the frequency of nausea and vomiting increases with larger total doses and target tissue volumes [29, 30].

CQ13. Do antiemetic treatments differ in equivalent regimens from those in standard regimens containing specific key agents?

Recommendation (Grade $\mathrm{C} 1$ ): the emetic risk should be assessed on the basis of the agent with the highest emetic risk, even for similar chemotherapeutic regimens that comprise several agents.

Most clinically used chemotherapeutic regimes include several drugs, although many variations of standard chemotherapeutic regimens containing similar key agents. Thus, it is important to assess the emetic risks of regimens according to the emetic risks of each agent in isolation.

CQ14. What clinical factors and patient backgrounds affect CINV?

Recommendation (Grade $\mathrm{C} 1$ ): treatment and patient factors affect the emetic risks of CINV. Treatment factors include emetogenicity and dosages of chemotherapeutic agents, and tissue targets and volumes of radiation therapy. Relevant patient factors include age, gender, and alcohol consumption.

The frequency and intensity of emesis from CINV are affected by numerous factors, including specific chemotherapeutic agents, regimens, dosages, schedules, routes of administration, and tissue targets and volumes for radiation therapy. In addition, patient factors such as age [31], gender [31, 32], alcohol consumption [33], and experience of nausea gravidarum affect the emetic effects of CINV. The NCCN guideline also suggests that bowel obstruction, vestibulopathy, brain metastasis, electrolyte dysbolism, uremia, opioid use, gastric atony, and mental disorders are potential risk factors for emesis. Accordingly, management of treatment-related emesis is well-established with consensus, whereas patient-oriented factors remain unclear.

CQ15. How should CINV be managed in pediatric patients with malignancies?

Recommendation (Grade C1): multidisciplinary management using $5 \mathrm{HT}_{3}$ receptor antagonists, corticosteroid, and other antiemetic agents control the emetic effects of CINV, even for pediatric patients.

In the last three decades, advances in cancer treatment, for example high dose methotrexate, cytarabine, cyclophosphamide, and hematinic stem cell transplantation, have led to long term prognoses for $\geq 70 \%$ of pediatric patients with malignancies. However, there are only a few reports with high level evidence about antiemetic treatment in pediatric patients from western populations [34-36]. Accordingly, they are treated with modified dosage on the basis of results of clinical trials on adult patients. Proper antiemetic treatments also enable pediatric patients to receive cancer chemotherapy without decline in QOL.

CQ16. Is it possible to discriminate nausea from anorexia, pyrosis, and dyspepsia? Which diseases produce symptoms of nausea and vomiting?

Recommendation (Grade B): no definitive evidence distinguishes nausea from anorexia, pyrosis, and dyspepsia. However, proton pump inhibitors (PPI) and $\mathrm{H} 2$ blockers are recommended for patients with these symptoms.

Recommendation (Grade C1): antiemetic agents should be used on the basis of accurate assessment of patient conditions.

Symptoms of anorexia, pyrosis, and dyspepsia are caused by several factors related to digestive dysfunction, and are frequently accompanied with nausea and other symptoms. Therefore, nausea induced by chemotherapy has not been strictly distinguished from other symptoms of digestive dysfunction. Nonetheless, PPI and H2-blockers are recommended as optional treatments for these symptoms [37].

In addition to treatments for CINV, patients with malignancies may suffer from nausea and vomiting as a result of the following conditions:

- Partial or complete bowel obstruction

- Vestibulopathy 
- Brain metastasis

- Electrolyte dysbolism (hypercalcemia, hyponatremia, and hyperglycemia)

- Uremia

- Other combinations of drugs, including opioids

- Gastric atony

- Anticipatory nausea and vomiting

CQ17. How are different forms of agents appropriately selected and used?

Recommendation (Grade B): patients should self-manage the use of oral agents. However, in circumstances in which nausea and vomiting prevent patients from taking oral treatments, optional intravenous administration should be considered.

Antiemetic agents are available in a variety of formulations for oral, rectal, intravenous, and intramuscular administration. A meta-analysis of randomized control trials showed equivalence of oral and intravenous $5 \mathrm{HT}_{3}$ receptor antagonists [38]. However, the cost effectiveness and convenience of administration of oral agents are superior to those of intravenous agents, particularly when administered as tablets that disintegrate orally. Nonetheless, intravenous agents may improve treatment adherence among pediatric patients.

CQ18. For which antiemetic drugs are pharmacokinetic interactions observed?

Recommendation (Grade B): it is essential that aprepitant is used carefully to avoid interactions with co-administered drugs, including some chemotherapeutic agents. Moreover, strict dose control of combined drug regimens according to patient conditions and disease backgrounds is critical.

Because aprepitant induces and inhibits the cytochrome P450 enzymes 3A4 (CYP3A4) and 2C9 (CYP2C9) it can alter plasma concentrations of co-administered drugs by interacting with these critical drug-metabolizing enzymes [39]. Chemotherapeutic agents that are metabolized by CYP3A4 include docetaxel, paclitaxel, etoposide, irinotecan, ifosphamide, imatinib, vinorelbine, vinblastine, and vincristine. Although doses were not adjusted for several chemotherapeutic agents used concurrently with aprepitant in phase III trials, these drugs should be used with caution $[40,41]$ because aprepitant interacts with several nonchemotherapeutic drugs, including warfarin, dexamethasone, and methylprednisolone. Concurrent use of aprepitant temporarily reduces prothrombin time-international normalized ratio (PT-INR) for patients receiving regimens that contain warfarin, necessitating anticoagulant monitoring for these patients [42]. Aprepitant also increases AUCs of the corticosteroids dexamethasone and methylprednisolone, necessitating appropriate reductions of corticosteroid doses (CQ7) [39]. However, to ensure anti-cancer effects, steroid doses should not be reduced in chemotherapeutic regimens for malignant lymphoma that include corticosteroid, despite concomitant use of aprepitant. Moreover, concurrent use of the CYP3A4 inhibitors ketoconazole, itraconazole, and erythromycin may increase aprepitant AUCs, whereas the CYP3A4 inducers carbamazepine, rifampicin, and phenytoin may reduce plasma levels of aprepitant.

CQ19. How are the effects of antiemetic treatment evaluated?

Recommendation (Grade A): the effects of antiemetic treatment should be assessed at every visit for outpatients, and within $24 \mathrm{~h}$ after administration of chemotherapy for admitted patients.

Recommendation (Grade $\mathrm{C} 1$ ): strict assessments require patients to report their conditions to medical staff by using self-reporting systems.

No definitive evidence or consensus has been published for assessment of antiemetic treatments. However, successful anticancer treatment depends on optimum patient assessments, and nausea and vomiting are observed for 31 and $20 \%$ of cancer patients, respectively [43]. Accordingly, the 2009 NCCN guidelines for palliative care recommend optimum screening for supportive care of all oncology patients according to their symptoms throughout the entire clinical course. Moreover, the RAND Cancer Quality-Assessing Symptoms Side Effects and Indicators of Supportive Treatment Project recommends symptom evaluations for all cancer patients, at every outpatient visit, and within $24 \mathrm{~h}$ of hospital admission. The 2009 NCCN Clinical Practice Guidelines for Antiemetics in Oncology suggest that prevention of nausea and vomiting is a primary objective. Hence, prophylactic treatment is mandatory for $\geq 4$ days, because the emetic risks of CINV continue for several days under conditions of highly or moderately emetogenic cancer chemotherapy [44]. Moreover, complete responses were reportedly not achieved for acute and delayed emesis, despite optimum prophylactic treatment [40].

Differential diagnosis of the causes of emesis are necessary during clinical evaluations (CQ14, 16). However, common terminology criteria for adverse events (CTCAE) may remain useful when chemotherapeutic regimens are applied, and are based on objective assessments by medical staff rather than subjective assessments by patients. Nonetheless, applicable patient directed subjective evaluations include the numerical rating scale (NRS), the visual analog scale (VAS), the verbal rating scale (VRS) and the Wong-Baker face rating scale. In addition, index of nausea, vomiting and retching (INVR) [44], Morrow assessment of nausea and emesis (MANE) [45], and functional living index-emesis (FLIE) scores [46] are also applicable as tools for evaluating longitudinal changes in emesis and the ensuing effects on quality of life. 
CQ20. How is occlusive ileus managed in cancer patients with advanced and metastatic status, including carcinomatous peritonitis?

Recommendation (Grade A): reduction of gastrointestinal pressure using a nasogastric tube or percutaneous gastrostomy is recommended. In addition, intraperitoneal injection of octreotide is recommended as a drug therapy for carcinomatous peritonitis.

Recommendation (Grade C1): such salvage surgery as bowel bypass may also be effective for patients who are not in a critical condition and have expectations of comparatively long survival. However, endoscopic stents are recommended to resolve symptoms of simple intestinal obstruction for patients with poor prognosis.

Bowel obstruction among patients with advanced metastatic disease reduces quality of life and causes difficulty in the continuation of anticancer treatments. Conservative treatments are usually used for such patients, because of poor prognosis as a result of advanced oncological status. However, $50 \%$ of colon cancer patients and 6-34\% of gynecologic cancer patients suffer from benign bowel obstructions [47], so accurate diagnoses is required.

CQ21. How are opioid-induced nausea and vomiting managed?

Recommendation (Grade B): emesis that is induced by opioid use should be managed by use of antiemetic treatments, although opioid rotation or changes in routes of administration may be considered.

Recommendation (Grade $\mathrm{C} 1$ ): prophylactic antiemetic treatments during opioid therapy may be useful despite the lack of high-level evidence of efficacy and safety.

The WHO ladder strongly recommends opioid use for oncological pain and cites high-level evidence of efficacy and safety. Moreover, three opioid receptors, the $\delta$ and $\kappa$ receptors for emetogenic functions and the $\mu$ receptor for antiemetic functions, have been characterized. Patients frequently suffer from constipation, sleepiness, nausea, and vomiting on initiation of opioid therapy. However, antiemetic treatments for opioid-induced emesis are important for successful pain control among cancer patients. Moreover, differential diagnosis of other causes is important in patients suffering from emesis after opioid treatments (CQ16). Nonetheless, opioid-induced emesis is usually relieved within a few days of opioid administration.

\section{Discussion}

The purpose of these practice guidelines is to disseminate treatment recommendations for daily practice according to $\mathrm{CQ}$ relating to medications. Thus, $21 \mathrm{CQ}$ pertaining to antiemetic therapy, including prophylactic and retrospective antiemetic treatments, were generated. In this literature review, most of the evidence was collected from foreign studies reporting high-level evidence that was acceptable for Japanese cancer patients. Therefore, these recommendations for standard therapy, depending on the grade of recommendation, were made on the basis of systematic review and meta-analysis of antiemetic therapy. Consequently, the CQs and their recommendations were similar to those published in previous guidelines that have been used globally. However, most reported evidence fails to consider ethnicity and Japanese health-care systems. Thus, after release of the guidelines, their penetration and dissemination to Japanese medical practitioners was evaluated. To this end, current use of antiemetic treatment in Japan was analyzed on the basis of data obtained from a nationwide questionnaire. Response was $88 \%$ and use of the guidelines $78 \%$ (in press).

\section{Conclusion}

In this manuscript we present, in English, of the 2010 JSCO clinical practice guidelines for antiemesis. High concordance with other antiemetic guidelines reflected their evidence-based nature. After release of these guidelines, high recognition and penetration was achieved for antiemetic medicine in Japan, thus contributing to effective antiemetic therapy for Japanese patients with malignancies.

Acknowledgments The authors thank Misao Oda for constant encouragement and support throughout the procedure, and Hitomi Sasaki for important contributions to the publication.

Conflict of interest Toshiaki Saeki received lecture fees from Taiho Pharmaceutical Co., Ltd./Novartis Pharma K.K. and research fundings from Taiho Pharmaceutical Co., Ltd./Daiichi Sankyo Co., Ltd. Keisuke Aiba received lecture fees from Taiho Pharmaceutical Co., Ltd. Kazuhiko Nakagawa received lecture fees from Astellas Pharma Inc. and research fundings from Taiho Pharmaceutical Co., Ltd/Ono Pharmaceutical Co., Ltd. Narikazu Boku received lecture fees from Taiho Pharmaceutical Co., Ltd./Ono Pharmaceutical Co., Ltd./Chugai Pharmaceutical Co., Ltd. and research fundings from Taiho Pharmaceutical Co., Ltd./Chugai Pharmaceutical Co., Ltd. Tadashi Ikeda received research funding from Chugai pharmaceutical Co., Ltd. The rest of authors have no conflict of interest.

\section{References}

1. NCCN (2009) Clinical practice guidelines in oncology-antiemesis-ver. 4

2. MASCC/ESMO-antiemetic guidelines $(2008,2010)$

3. ASCO (2006) Guidelines for antiemetics in oncology: update

4. www.agreetrust.org/resource-centre/agree-ii/. Accessed June 2009

5. The Cochrane Library (2009) issue 3

6. Kimura K, Yamada K, Uzuka Y et al (1982) Phase I study of $\mathrm{N}^{4}$-behenoyl-1-1-beta-D-arabinofuranosylcytosine and its phase II study in adult acute leukemia. Current chemotherapy and immunotherapy. In: Proceedings of the 12th International Congress of Chemotherapy, pp 1306-1308 
7. Yana T, Negoro S, Takada M et al (2007) Phase II study of amrubicin in previously untreated patients with extensive-disease small cell lung cancer: West Japan Thoracic Oncology Group (WJTOG) study. Invest New Drugs 25:253-258

8. Roila F, Hesketh PJ, Herrstedt J et al (2006) Prevention of chemotherapy- and radiotherapy-induced emesis: results of the 2004 Perugia International Antiemetic Consensus Conference. Ann Oncol 17:20-28

9. Herrstedt J, Rolia F (2008) Chemotherapy-induced nausea and vomiting: ESMO clinical recommendations for prophyraxis. Ann Oncol 19:110-112

10. The Italian Group for Antiemetic Research (2000) Dexamethasone alone or in combination with ondansetron for the prevention of delayed nausea and vomiting induced by chemotherapy. N Engl J Med 342:1554-1559

11. Saito M, Aogi K, Sekine I et al (2009) Palonosetron plus dexamethasone versus granisetron plus dexamethasone for prevention of nausea and vomiting during chemotherapy: a double-blind, double-dummy, randomized, comparative phase III trial. Lancet Oncol 10:115-124

12. Aapro MS, Alberts DS (1981) High-dose dexamethasone for prevention of cisplatin-induced vomiting. Cancer Chemother Pharmacol 7:11-14

13. Ioannidis JP, Hesketh PJ, Lau J (2000) Contribution of dexamethasone to control chemotherapy-induced nausea and vomiting; a meta-analysis of randomized evidence. J Clin Oncol 18:3409-3422

14. Grunberg SM (2007) Antiemetic activity of corticosteroids in patients receiving cancer chemotherapy: dosing, efficacy, and tolerability analysis. Ann Oncol 18:233-240

15. Sekine S, Nishiwaki Y, Kakinuma R et al (1997) Phase II study of high-dose dexamethasone-based association in acute and delayed high-dose cisplatin-induced emesis JCOG study 9413. Br J Cancer 76:90-92

16. Glare P, Pereira G, Kristjanson LJ et al (2004) Systematic review of the efficacy of antiemetics in the treatment of nausea in patients with far-advanced cancer. Support Care Cancer 12:432-440

17. Bruera E, Moyano JR, Sala R et al (2004) Dexamethasone in addition to metoclopramide for chronic nausea in patients with advanced cancer: a randomized controlled trial. J Pain Symptom Manage 28:381-388

18. Cancer Care Ontario. The role of neurokinin-1 receptor antagonists in the prevention of emesis due to high-dose cisplatin. http:// www.cancercare.on.ca/pdf/pebc12-4f.pdf. Accessed June 2009

19. Ettinger DS, Bierman PJ, Bradbury B et al (2007) Antiemesis. J Natl Compr Canc Netw 5:12-33

20. Valle JW, Wasan HS, Palmer DD et al (2009) Gemcitabine with or without cisplatin in patients with advanced or metastatic biliary tract cancer $(\mathrm{ABC})$ : results of a multicenter randomized phase III trial (the UK ABC-02 trial). J Clin Oncol 27:15s (suppl; abstr 4503)

21. Williams SD, Birch R, Einhorn LH et al (1987) Treatment of disseminated germ-cell tumors with cisplatin, bleomycin, and either vinblastine or etoposide. N Engl J Med 316:1435-1440

22. Morrow GR, Morrel C (1982) Behavioral treatment for the anticipatory nausea and vomiting induced by cancer chemotherapy. N Engl J Med 307:1476-1480

23. Morrow GR, Lindke J, Black PM et al (1991) Predicting development of anticipatory nausea in cancer patients: prospective examination of right clinical characteristics. J Pain Symptom Manage 6:215-223

24. Andrykowski MA, Jacobsen PB, Marks E et al (1988) Prevalence, predictors, and course of anticipatory nausea in women receiving adjuvant chemotherapy for breast cancer. Cancer 62:2607-2613

25. Alba E, Bastus R, de Andres L et al (1989) Anticipatory nausea and vomiting: prevalence and predictors in chemotherapy patients. Oncology 46:26-30
26. Morrow GR (1982) Prevalence and correlates of anticipatory nausea and vomiting in chemotherapy patients. J Natl Cancer Inst 68:585-588

27. Malik IA, Khan WA, Qazilbash M et al (1995) Clinical efficacy of lorazepam in prophylaxis of anticipatory, acute, and delayed nausea and vomiting induced by high doses of cisplatin. A prospective randomized trial. Am J Clin Oncol 18:170-175

28. Razavi D, Delvaux N, Farvacques C et al (1993) Prevention of adjustment disorders and anticipatory nausea secondary to adjuvant chemotherapy: a double-blind, placebo-controlled study of assessing the usefulness of alprazolam. J Clin Oncol 11:1384-1390

29. Feyer PC, Stewart AL, Titlbach OJ et al (1998) Aetiology and prevention of emesis induced by radiotherapy. Support Care Cancer 6:253-260

30. Spitzer TR, Friedman CJ, Bushnell W et al (2000) Double-blind, randomized, parallel-group study on the efficacy and safety of oral granisetron and oral ondansetron in the prophylaxis of nausea and vomiting in patients receiving hyperfractionated total body irradiation. Bone Marrow Transplant 26:203-210

31. Tonato M, Rolia F, Del Favero A et al (1991) Methodology of antiemetic trials. Ann Oncol 2:107-114

32. Rolia F, Tonato M, Basurto C et al (1987) Antiemetic activity of high doses of metoclopramide combined with methylprednisolone versus metoclopramide alone in cisplatin-treated cancer patients: a randomized double-blind trial of the Italian Oncology Group for Clinical Research. J Clin Oncol 5:141-149

33. Sullivan JR, Leyden MJ, Bell R et al (1983) Decreased cisplatininduced nausea and vomiting with chronic alcohol ingestion. $\mathrm{N}$ Engl J Med 309:796

34. Hasler SB, Hirt A, Luethy AR et al (2008) Safety of ondansetron loading doses in children with cancer. Support Care Cancer $16: 469-475$

35. Sepulveda-Vildosola AC, Betanzos-Cabrera Y, Lastiri GG et al (2008) Palonosetron hydrochloride is an effective and safe option to prevent chemotherapy-induced nausea and vomiting in children. Arch Med Res 39:601-606

36. Gore L, Chawla S, Petrilli A et al (2009) Aprepitant in adolescent patients for prevention of chemotherapy-induced nausea and vomiting: a randomized double-blind, placebo-controlled study of efficacy and tolerability. Pediatr Blood Cancer 52:242-247

37. Talley NJ, Meineche-Schmidt V, Pare P et al (1998) Efficacy of omeprazole in functional dyspepsia: double-blind, randomized, placebo-controlled trials. Aliment Pharmacol Ther 12:1055-1065

38. Giglio A, Soares HP, Caparroz C et al (2000) Granisetron is equivalent to ondansetron for prophylaxis of chemotherapyinduced nausea and vomiting: results of a meta-analysis of randomized controlled trials. Cancer 89:2301-2308

39. McCrea JB, Majumdar AK, Goldberg MR et al (2003) Effects of the neurokinin1 receptor antagonist aprepitant on the pharmacokinetics of dexamethasone and methylprednisolone. Clin Pharmacol Ther 74:17-24

40. Hesketh PJ, Grunberg SM, Gralla RJ et al (2003) The oral neurokinin-1antagonist aprepitant for the prevention of chemotherapyinduced nausea and vomiting: a multinational, randomized, double-blind, placebo-controlled trial in patients receiving high-dose cisplatin-the Aprepitant Protocol 052 Study Group. J Clin Oncol 21:4112-4119

41. Poli-Bigelli S, Rodrigues-Pereira J, Carides AD et al (2003) Addition of the neurokinin-1 receptor antagonist aprepitant to standard antiemetic therapy improves control of chemotherapy induced nausea and vomiting: results from a randomized, double-blind, placebo-controlled trial in Latin America. Cancer 97:3030-3038 
42. Depre M, Van Hecken A, Oeyen M et al (2005) Effect of aprepitant on the pharmacokinetics and pharmacodynamics of warfarin. Eur J Clin Pharmacol 61:341-346

43. Teunissen SC, Wesker W, Kruitwagen C et al (2007) Symptom prevalence in patients with incurable cancer: a systematic review. J Pain Symptom Manage 34:94-104

44. Rhodes VA, McDaniel RW (1999) The index of nausea, vomiting, and retching: a new format of the index of nausea and vomiting. Oncol Nurs Forum 26:889-894

45. Morrow GR (1992) A patient report measure for the quantification of chemotherapy induced nausea and emesis: psychometric properties of the Morrow assessment of nausea and emesis (MANE). Br J Cancer 66:72-74

46. Lindley CM, Hirsch JD, O'Neill CV et al (1992) Quality of life consequences of chemotherapy-induced emesis. Qual Life Res 66:72-74

47. Ripamonti C, De Conno F, Ventafridda V et al (1993) Management of bowel obstruction in advanced and terminal cancer patients. Ann Oncol 4:15-21 